\title{
Hirticlavula elegans, a new clavarioid fungus from Scandinavia
}

\author{
JENS H. PETERSEN, MARIE L. DAVEY and THOMAS LÆSSØE
}

\begin{abstract}
PETERSEN, J.H., DAVEY, M.L. \& LÆSSØE, T. 2014: Hirticlavula elegans, a new clavarioid fungus from Scandinavia - Karstenia 54: 1-8. HELSINKI. ISSN 0453-3402.

Based on material from Denmark and Norway the new clavarioid genus Hirticlavula with one species, $H$. elegans, is described. It produces tiny, hyaline white basidiomata with upward pointing blunt ended hairs. Phylogenetic analysis of the LSU region of rDNA strongly supports the inclusion of this fungus in the Clavariaceae sensu stricto where it occupies a position sister to all members of Clavaria, Camarophyllopsis, and Hodophilus. It has been found from May to October fruiting on wet, rotten hardwood bark on the ground, and its lignicolous, saprophytic nutritional mode further distinguishes it from other members of the Clavariaceae.
\end{abstract}

Key words: Clavariaceae, taxonomy, phylogeny, Hirticlavula

Jens H. Petersen, MycoKey, Nøruplundvej 2, 8400 Ebeltoft, Denmark. Corresponding author, e-mail \& website: info@jenshpetersen.dk,www.mycokey.com.

Marie L. Davey, Department of Biosciences, University of Oslo, PO Box 1066 Blindern,0316Oslo,Norway; e-mail:m.l.davey@ibv.uio.no

Thomas Lassøe, Department of Biology/Natural History Museum of Denmark, University of Copenhagen, Universitetsparken 15, 2100 København Ø; e-mail: thomasl@bio.ku.dk

\section{Introduction}

One may think that the fungi of the well researched Northern Europe can no longer offer significant surprises. But this is not so: mycologists and forayers continue to discover remarkable new genera and species from this area. Here, we describe a new clavarioid taxon characterised by minute, somewhat typhuloid, hairy fruit bodies on rotten bark. It is currently known from several collections from Denmark and Norway with the first collection dating back to 1995 . It has been reported provisionally by Jordal \& Læssøe (2009), and has also featured in various versions of MycoKey (Læssøe \& Petersen 2003). Initial attempts at sequencing material for phylogenetic reconstruction in 2005 were unsuccessful. Following successful sequencing based on Norwegian material from 2011, a formal description can now be proposed.

Typhuloid fungi with or without sclerotia have been monographed by Corner $(1950,1970)$ and by Berthier (1976). In these works no fungi with characters approaching those of the fungus described below can be found. In addition, the fungus was not covered in a comprehensive 
treatment of mainly Iberian cantharelloid and clavariod fungi (Olariaga 2009) nor was anything similar treated by Birkebak et al. (2013).

\section{Material and methods}

\section{DNA sequencing and phylogenetic analysis}

Three entire basidiomata were crushed in a single Eppendorf tube using a Retsch ball mill (Retsch, Dusseldorf, Germany) and their genomic DNA was extracted using a modified CTAB-based extraction protocol in accordance to Murray \& Thompson (1980) and Gardes \& Bruns (1993). The large subunit (LSU) region of ribosomal DNA was amplified with the forward and reverse primer set LROR and LR7 (Vilgalys \& Hester 1990) using illustra PuReTaq Ready-To-Go PCR Beads (GE Healthcare, Piscataway, NJ, USA) according to the manufacturer's instructions. Amplicons were sequenced with an ABI 3100 automated sequencer (Applied Biosystems Inc., Foster City, CA, USA) and the primers LROR, LR3R, LR5 and LR7 (Vilgalys \& Hester 1990). A data matrix was assembled from LSU sequences of Hirticlavula elegans and members of the Clavariaceae sensu Dentinger \& McLaughlin (2006), as well as clavarioid fungi from other groups (i.e. Mucronella, Macrotyphula, Typhula). The matrix was aligned using MAFFT version 6.717 (Katoh \& Toh 2008), the resulting alignment was manually verified, and then Gblocks v0.91b (Castresana 2000) was used to remove ambiguously aligned bases. The Bayesian information criterion in jModelTest v0.1.1 (Guindon \& Gascuel 2003, Posada 2008) was used to determine the best-fit model of evolution, which was then implemented in both maximum likelihood and Bayesian analyses. GARLI v 1.0 (Zwickl 2006) was used to determine the most likely tree and maximum likelihood bootstrap support for the dataset. Bayesian analyses were conducted using Mr.Bayes version 3.2 (Ronquist \& Huelsenbeck 2003) with two independent runs of four Markov Chain Monte Carlo chains with $1.0 \times 107$ generations each, sampling trees every 1000 th generation. A final standard deviation of $<0.01$ for the split frequency was interpreted to reflect convergence. The first $25 \%$ of sampled trees were discarded as burn-in and posterior probabilities for each node of the $50 \%$ majority rule consensus tree were recorded.

\section{Morphology}

The macroscopic images were taken with a Leica M 420 macroscope equipped with various analogue and digital cameras. Pictures are stacked using Zerine Stacker and post processed with Adobe Photoshop. Observations of microscopic characters and micrographs were made with Leica Orthoplan and Olympus BX50 microscopes. Measurements were made on dead material in ca 5\% ammoniacal congo red.

\section{Results}

The aligned matrix of LSU sequences included 94 taxa and 1288 characters, and the GTR $+\mathrm{I}+\mathrm{G}$ model was selected by jModelTest as the best-fit model of evolution for the data. Results of the maximum likelihood bootstrap analyses and the Bayesian inference are shown on the maximum likelihood tree (-lnL -11336.51) (Fig. 1). Hirticlavula elegans is included within the well supported Clavariaceae sensu stricto (see Dentinger \& McLaughlin 2006). It is supported as sister to a clade comprised of the genera Clavaria, Camarophyllopsis, and Hodophilus (100\% Bayesian Posterior Probability, BPP and 78\% Maximum Likelihood Bootstrap Proportion, BP) that is equivalent to Clade 4 as described in Birkebak et al. (2013). Hyphodontiella is weakly supported as sister to the Hirticlavula-Clavulariaceae clade (59 BPP\%, 53\% BP). In all analyses, Hirticlavula is remote from all typhuloid taxa.

Hirticlavula J.H. Petersen \& Læssøe, gen. nov.

\section{MycoBank no.: MB 808059}

Basidiomata club shaped, small, stipe hirsute, without sclerotium. Hyphal system monomitic, hyphae non-inflated. Hairs unbranched, septate, cyanophilous, up to $250 \mu \mathrm{m}$ long, widening towards the obtuse apex. Basidia holobasidia without clamps. Spores hyaline, more or less cyanophilous, smooth.

Type: Hirticlavula elegans J.H. Petersen \& Læssøe

Hirticlavula elegans J.H. Petersen \& Læssøe, sp. nova - Figs. 2-5

MycoBank no.: MB 808060

Holotype: Norway. Vestfold. Sem, Gullkronenes Naturreservat, Lille Gullkrone, 59.2854179 / 10.3826165, on Quercus bark on the ground in mature oak woodland, 25.X.2013 Laessøe, JHP-13.364 (O, isotype in TUR). 


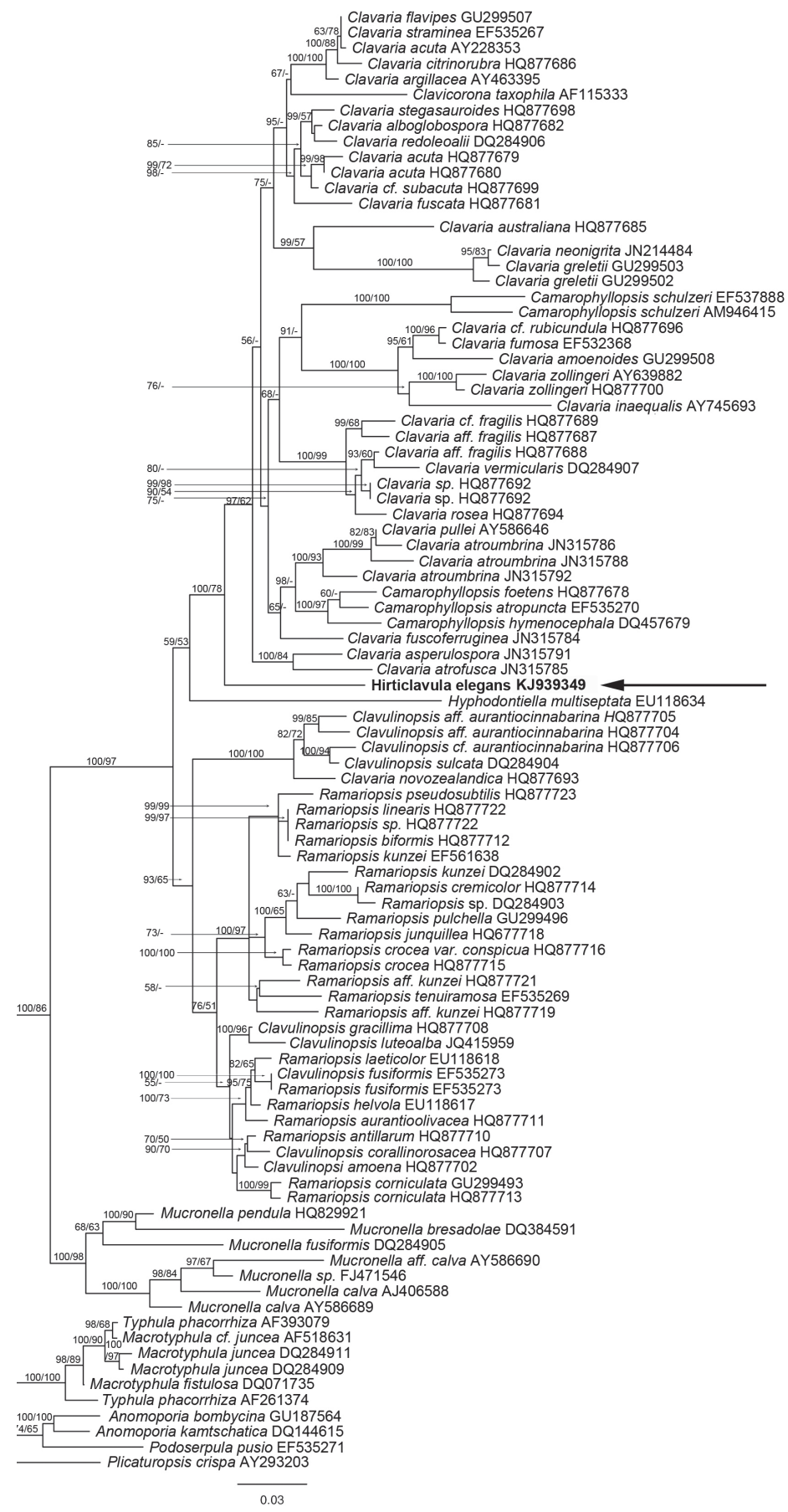

Clavaria

Camarophyll-

opsis

Clavaria

Hodophilus

Hirticlavula Hyphodontiella

Clavulinopsis

Ramariopsis

Mucronella

Typhulaceae

Amylocorticiales

Fig 1. Maximum likelihood tree inferred from a dataset of large subunit rDNA sequences showing the placement of Hirticlavula elegans among other clavarioid taxa. Support values are given above the branches as Bayesian posterior probability/bootstrap proportion. Accession numbers for sequences retrieved from GenBank are given following the sequence name. 
Basidiomata 800-1100 $\mu \mathrm{m}$ high, translucent white, with a 600-800 $\mu \mathrm{m}$ long and 40-60 $\mu \mathrm{m}$ thick, hairy stem abruptly widening into a 230-260 x 90-200 $\mu \mathrm{m}$ large, solid, fertile head. Dried material with a cream tinge and hardly collapsed. Hyphal structure monomitic, without clamps; hyphae in stem parallel, non-inflated, 1-2 $\mu \mathrm{m}$ wide, more intertwined and gnarled at insertion point. Hairs straight, pointing upwards at an oblique angle, unbranched, slightly thickwalled, remotely septate, $150-250 \times 1.5-2.5$ $\mu \mathrm{m}$ (base) and 3-4.5 $\mu \mathrm{m}$ thick at the rounded \pm clavate apex; cells 10-30 $\mu \mathrm{m}$ long. Basidia without clamps, cyanophilous, 14-22 × 3-5.5 $\mu \mathrm{m}$, with four, curved and remarkably thin, 4-5 $\mu \mathrm{m}$ long sterigmata. Spores hyaline, cyanophilous or with a few cyanophilous particles inside, smooth, broadly ellipsoid, 4.5-6.5 × 3-4.2 $\mu \mathrm{m}$, $\mathrm{Q}=1.2-1.5$, mean $\mathrm{Q}=1.36(\mathrm{n}=15)$, apiculus up to $0.8 \mu \mathrm{m}$ long. Crystals not prominent.

The basidiomata do not emerge from a sclerotium, but arise directly on bark or rarely wood from hard wood trees, two collec- tions on Quercus, another on Salix, one on Corylus and one on undetermined hardwood.

Additional specimens studied: DENMARK. Jutland. Skindbjerglund, south of Aalborg, 56.88889 / 9.923832, on bark on Quercus trunk on the ground, 30.IX.1995 Vesterholt, JHP-95.177 (C); Store Vildmose, Sandelsbjerg, 57.220723 / 9.759979, on rotten Salix bark on the ground in moist Salix carr, 16.V.2005 Huhtinen JHP-05.067/JHP-05.068 (C, TUR). NORWAY. Akershus. Frogn, Håøya, 59.104221 / 10.212019, on rotten hard wood bark (Betula?), 2.IX.2011 Loessøe. Møre \& Romsdal. Nesset, under Rangåfjellet, on decayed Corylus wood, 62.461407 / 8.221528; MQ 5949926079 , 26.IX.2008 Loessøe \& Nielsen TL-13513 (C).

\section{Discussion}

The distinguishing characters of this species are its very small basidiomata and peculiar hairs. The up to $1.1 \mathrm{~mm}$ high basidiomata are well outside

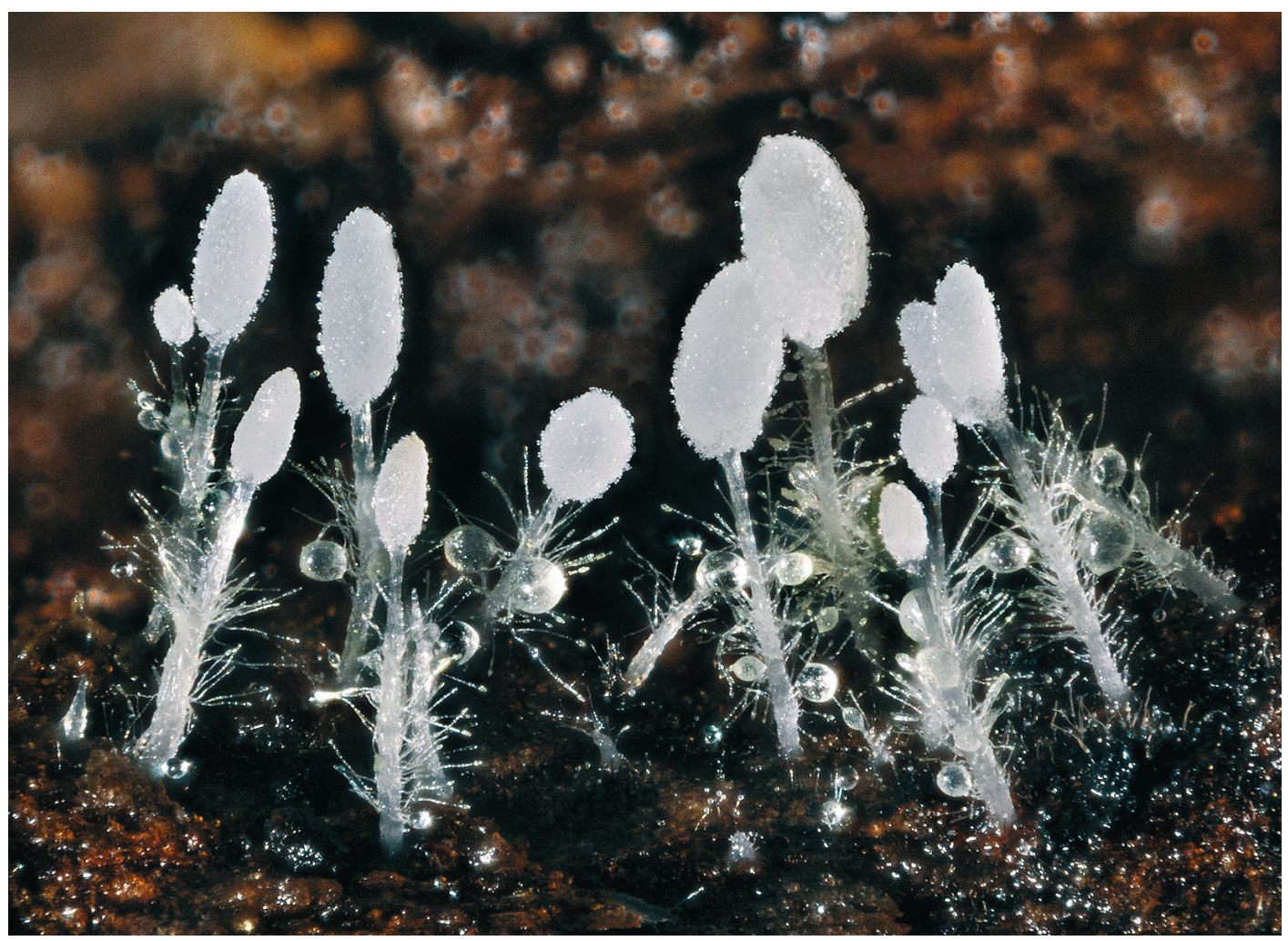

Fig. 2. Hirticlavula elegans (holotype). - Photo: J.H. Petersen. 

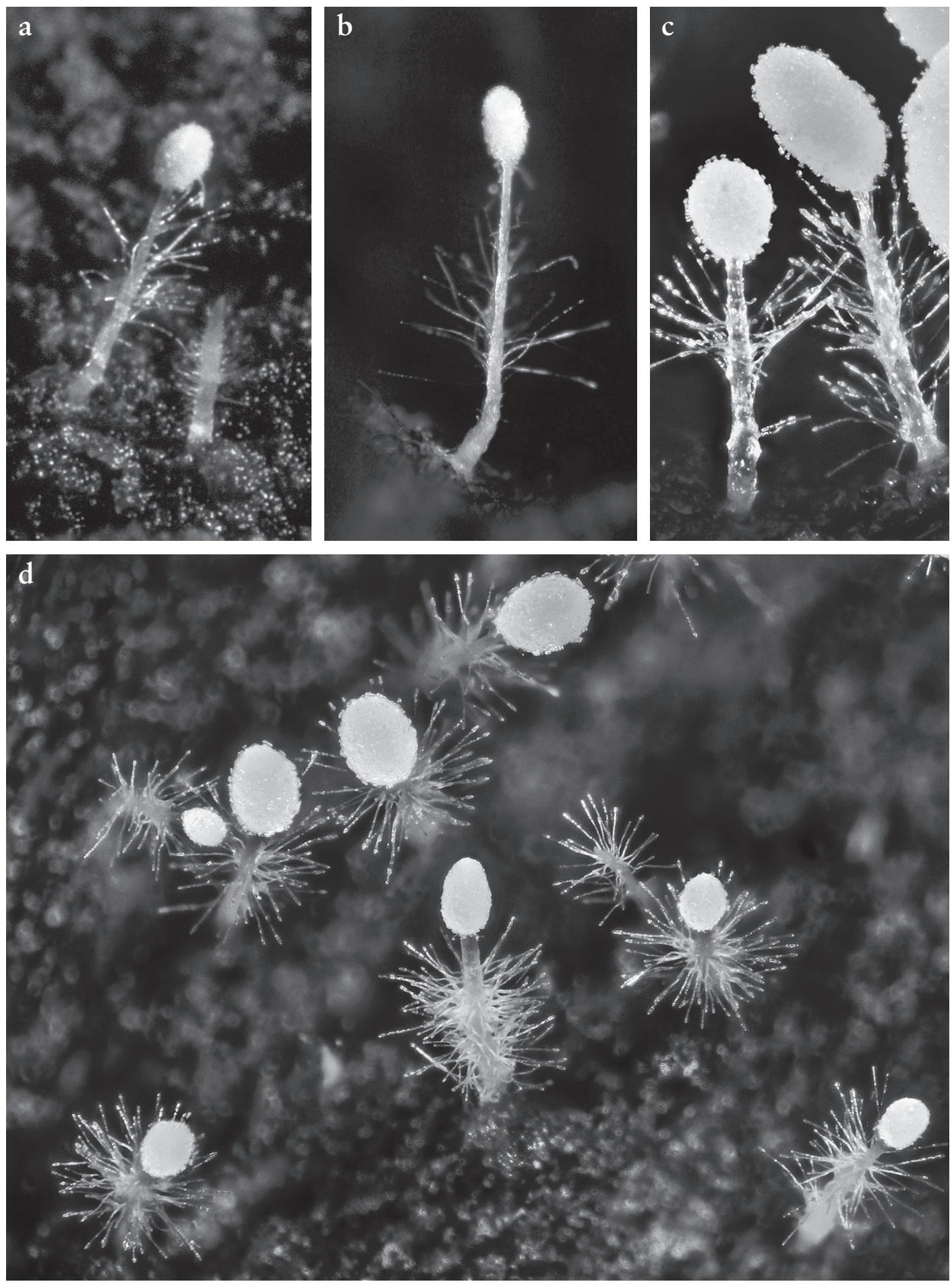

Fig. 3. Basidiomata of Hirticlavula elegans. $\mathrm{a}=J H P-95.117, \mathrm{~b}=J H P-05.068, \mathrm{c}-\mathrm{d}=J H P-13.364$ (holotype). - Photos: J.H. Petersen 

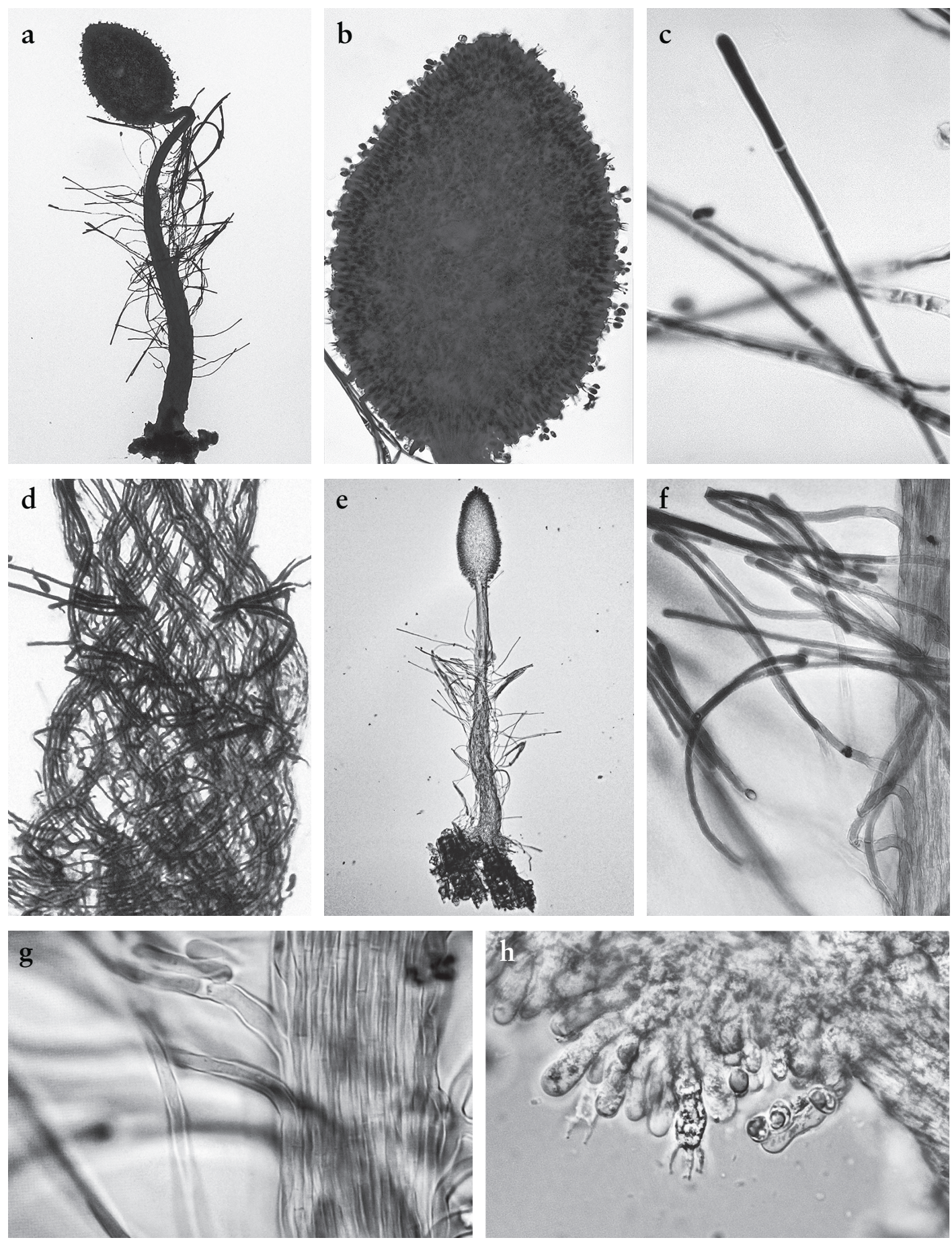

Fig. 4. Light microscope photographs of Hirticlavula elegans. a-c $=J H P-95.117, \mathrm{~d}-\mathrm{h}=J H P-13.364$. $\mathrm{a}=$ whole basidiome, $\mathrm{b}=$ head with basidia and spores, $\mathrm{c}=$ rounded apices of hairs, $\mathrm{d}=$ spiralling hyphae of stem base, $\mathrm{e}=$ whole basidiome, $\mathrm{f}=$ hairs, $\mathrm{g}=$ hairs raising from stipe tissue, $\mathrm{h}=$ basidia and spores; $\mathrm{a}-\mathrm{g}$ in cotton blue, $\mathrm{h}$ in water. - Photos: J.H. Petersen \& T. Læssøe. 
the range of all other known members of the Clavariaceae sensu stricto but are found elsewhere among more distantly related clavarioid fungi, e.g. the genera Typhula, Pistillina and Pterula. The hairs of Hirticlavula elegans originate from the outer hyphae of the stipe and point upwards, as if aiming to surround the fertile head. They are not merely branched hyphae, as the sparsely septate, rather irregular hairs often seen on the stipes of species of Typhula, Pistillina and Pterula, but are highly specialised structures with numerous septa and ending in a characteristic, rounded apex. While the hairs of all other known clavarioid fungi narrow towards the apex, the hairs of this species widen. Hirticlavula elegans is strongly supported as sister to all other members of Clavaria, Camarophyllopsis, and Hodophilus in phylogenetic analyses of the LSU region, and can be distinguished from these genera not only based on its minute size and diagnostic hairs, but also based on its ecology. While members of the Clavariaceae sensu stricto can be classified as biotrophic based on stable isotope analysis (Birkebak et al. 2013), H. elegans is lignicolous and saprotrophic. Given that Hyphodontiella, another wood-inhabiting genus within the clavarioid clade, is identified as sister to the HirticlavulaClavariaceae clade, further multigene analysis of the systematic positions within this group could provide valuable insight into the evolution of nutritional mode transitions in the clavarioid fungi.

It is rather surprising that Hirticlavula can produce basidiomata from May through to October. We do not know other tiny clavarioid fungi with such a long fruiting period. The unique morphology, ecology, and phylogenetic position of this fungus all suggest that it represents an undescribed genus closely related to the Clavaria/Camarophyllopsisclade within the Clavariaceae sensu stricto.

Acknowledgements: Jan Vesterholt $(\dagger)$ and Seppo Huhtinen are thanked for placing their material at our disposal. Risken, Molde- og omegn Soppforening and Wenche Johansen are thanked for inviting and hosting $\mathrm{TL}$ at the Eikesdalen Foray. Ernest Emmett is thanked for checking the English language.

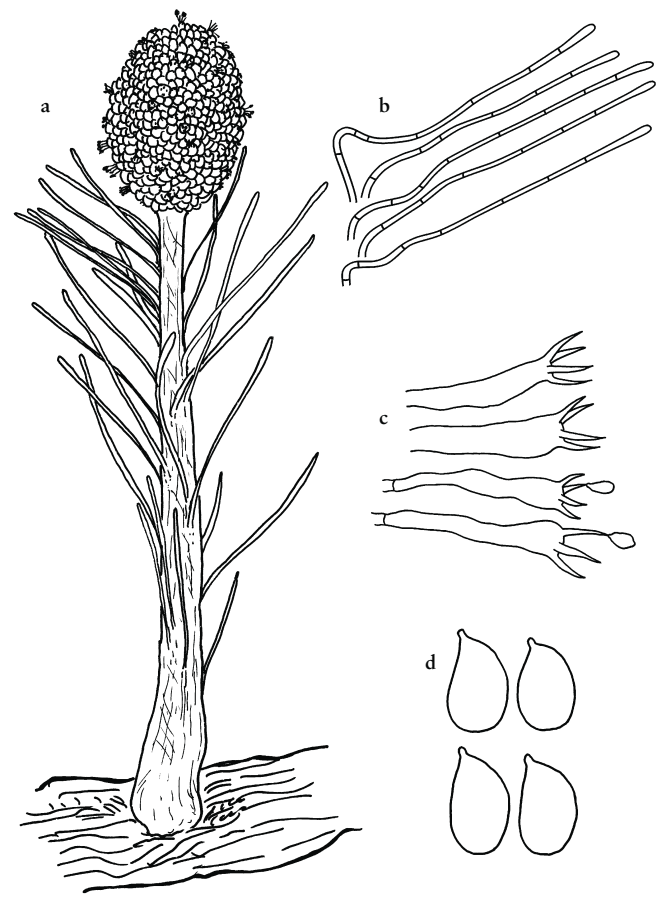

Fig. 5. Hirticlavula elegans (JHP-95.117). a = whole basidiome, $\mathrm{b}=$ hairs, $\mathrm{c}=$ basidia, $\mathrm{d}=$ spores. - Drawings: J.H. Petersen.

\section{References}

Berthier, J. 1976: Monographie des Typhula Fr., Pistillaria Fr. et genres voisins. - Bulletin de la Société Linneene de Lyon 45: 1-23.

Birkebak, J.M., Mayor, J.R., Ryberg, K.M. \& Matheny, P.B. 2013: A systematic, morphological, and ecological overview of the Clavariaceae (Agaricales). - Mycologia 105: 896-911.

Castresana, J. 2000: Selection of conserved blocks from multiple alignments for their use in phylogenetic analysis. - Molecular Biology and Evolution 17: 540-552.

Corner, E.J.H. 1950: A monograph of Clavaria and allied genera. - 740 pp., tab. 1-16. Oxford University Press. London.

Corner, E.J.H. 1970: Supplement to "A monograph of Clavaria and allied genera". - Nova Hedwigia, Beih. 33: 1-299, pl. 1-4.

Dentinger, B.T. \& McLaughlin, D.J. 2006: Reconstructing the Clavariaceae using nuclear large subunit rDNA sequences and a new genus segregated from Clavaria. - Mycologia 98: 746-762.

Gardes, M. \& Bruns, T. 1993: ITS primers with enhanced specificity for basidiomycetes-application to the identification of mycorrhizae and rusts. - Molecular Ecology 2: 113-118. 
Guindon, S. \& Gascuel, O. 2003: A simple, fast, and accurate algorithm to estimate large phylogenies by maximum likelihood. - Systematic Biology 52: 696704.

Jordal, J.B. \& Læssøe, T. (eds.) 2009: Rapport fra Riskens soppkurs i Eikesdalen 25.-28.09.2008 [A report on the fungus workshop held at Eikesdalen 25-29 Sept. 2008]

Katoh, K. \& Toh, H. 2008: Recent developments in the MAFFT multiple sequence alignment program. Briefings in Bioinformatics 9: 286-298.

Læssøe, T. \& Petersen, J.H. 2003: MycoKey 1.0 - an interactive identification system to fungal genera.

Murray, M. \& Thompson, W. 1980: Rapid isolation of high molecular weight plant DNA. - Nucleic Acids Research 8: 4321.

Olariaga, I. 2009: The order Cantharellales in the Iberian Peninsula and Balearic Islands. -547 pp. Thesis, Uni- versidad del Pais Vasco.

Posada, D. 2008: jModelTest: Phylogenetic Model Averagin. - Molecular Biology and Evolution 25: 12531256.

Ronquist, F. \& Huelsenbeck, J.P. 2003: MRBAYES 3: Bayesian phylogenetic inference under mixed models. - Bioinformatics 19: 1572-1574.

Vilgalys, R. \& Hester, M. 1990: Rapid genetic identification and mapping of enzymatically amplified ribosomal DNA from several Cryptococcus species. Journal of Bacteriology 172: 4238-4246.

Zwickl, D.J. 2006: Genetic algorithm approaches for the phylogenetic analysis of large biological sequence datasets under the maximum likelihood criterion. Ph.D. dissertation, The University of Texas at Austin. 